\title{
Thermolysis of 2,2-dimethoxy-5,5-dimethyl- $\Delta^{3}$ - 1,3,4-oxadiazoline studied with photoelectron spectroscopy. He(l) photoelectron spectrum of dimethoxycarbene
}

\author{
H.M. Muchall, N.H. Werstiuk, B. Choudhury, J. Ma, J. Warkentin, and J.P. \\ Pezacki
}

\begin{abstract}
Gas phase thermolysis of 2,2-dimethoxy-5,5-dimethyl- $\Delta^{3}$-1,3,4-oxadiazoline (1) in an ultraviolet photoelectron spectrometer by means of a $\mathrm{CW} \mathrm{CO}$ laser as directed heat source at $26 \mathrm{~W}$ gave a complex PE spectrum that included ionization bands belonging to acetone, tetramethoxyethylene (3), and dimethyl oxalate (4). Subtraction of the spectra of acetone, $\mathbf{3}$, and $\mathbf{4}$ from the pyrolysis spectrum of $\mathbf{1}$ left a simple PE spectrum that is attributed to dimethoxycarbene (2) along with some ethane. Becke3LYP/6-31+G* calculations gave first adiabatic and vertical ionization potentials of 2 as well as orbital energies that are in perfect agreement with experimental values. From the available experimental and calculational data, 2 is assumed to adopt a $w$ conformation.
\end{abstract}

Key words: dimethoxycarbene, 2,2-dimethoxy- $\Delta^{3}$-1,3,4-oxadiazoline, tetramethoxyethylene, He(I) photoelectron spectroscopy, thermolysis.

\begin{abstract}
Résumé : La thermolyse en phase gazeuse de la 2,2-diméthoxy-5,5-diméthyl- $\Delta^{3}$-1,3,4-oxadiazoline (1) dans un spectromètre photoélectronique ultraviolet, à l'aide d'un laser à $\mathrm{CO}_{2} \mathrm{CW}$ utilisé comme source dirigée de chaleur à $26 \mathrm{~W}$, conduit à un spectre PE complexe comportant des bandes d'ionisation appartenant à l'acétone, au tétraméthoxyéthylène (3) et à l'oxalate de diméthyle (4). Si l'on soustrait les spectres de l'acétone et ceux des composés $\mathbf{3}$ et $\mathbf{4}$ du spectre de pyrolyse du composé $\mathbf{1}$, on obtient un spectre PE résiduel qui a été attribué au diméthoxycarbène (2) en présence de faibles quantités d'éthane. Des calculs de Becke3LYP/6-31+G* ont permis d'obtenir les premiers potentiels d'ionisation adiabatique et verticale de l'entité 2 ainsi que des énergies d'orbitales qui sont en parfait accord avec les valeurs expérimentales. Sur la base des données expérimentales et résultats des calculs, on peut faire l'hypothèse que l'entité $\mathbf{2}$ adopte une conformation $w$.
\end{abstract}

Mots clés : diméthoxycarbène, 2,2-diméthoxy- $\Delta^{3}$-1,3,4-oxadiazoline, tétraméthoxyéthylène, spectroscopie photoélectronique $\mathrm{He}(\mathrm{I})$, thermolyse.

[Traduit par la rédaction]

The combination of photoelectron (PE) spectroscopy with quantum chemical calculations of molecular orbital eigenvalues and eigenvectors gives information about the electronic structure and bonding of stable as well as transient species that is provided by no other technique. PE spectra of transient carbenes are very rare (1) due to the high reactivity of these species, which requires special instrumentation. Usually, reactive intermediates are generated pyrolytically from thermally labile

Received September 25, 1997.

H.M. Muchall, ${ }^{1}$ N.H. Werstiuk, ${ }^{1}$ B. Choudhury, J. Ma, J. Warkentin, and J.P. Pezacki. Department of Chemistry, McMaster University, Hamilton, ON L8S 4M1, Canada.

1 Authors to whom correspondence may be addressed. Telephone: (905) 525-9140. Fax: (905) 522-2509. E-mail: muchall@mcmaster.ca,werstiuk@mcmaster.ca precursors using electrically heated furnaces that are several centimeters in length (2). Yet carbenes have to be generated close to the ionization beam to minimize the incursion of reactions like rearrangement, fragmentation, or dimerization. Our unique ultraviolet $\mathrm{PE}$ spectrometer - $\mathrm{CW} \mathrm{CO}_{2}$ laser apparatus (3) allows us to use the laser as a directed heat source to produce a hot zone as short as $1 \mathrm{~mm}$ in length on the tip of a quartz tube positioned at about $1 \mathrm{~cm}$ from the point of intersection with the ionization beam. We used this setup successfully to obtain PE spectra of short-lived reactive species such as benzazete and $o$-benzyne (4), 1,2-cyclohexadiene (5), 1-(2thiaindane)ketene and benzocyclobutenethione (6), as well as $p$-substituted phenylketenes (7) through pyrolyses of suitable precursors (Scheme 1).

We decided to study the thermal gas phase decomposition of 2,2-dimethoxy-5,5-dimethyl- $\Delta^{3}-1,3,4$-oxadiazoline (1) (8), because thermolysis in solution had shown formation of 
Scheme 1.<smiles>COC1(OC)N=NC(C)(C)O1</smiles><smiles></smiles>

1

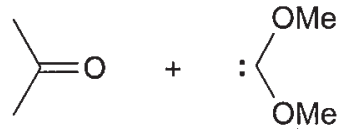

2
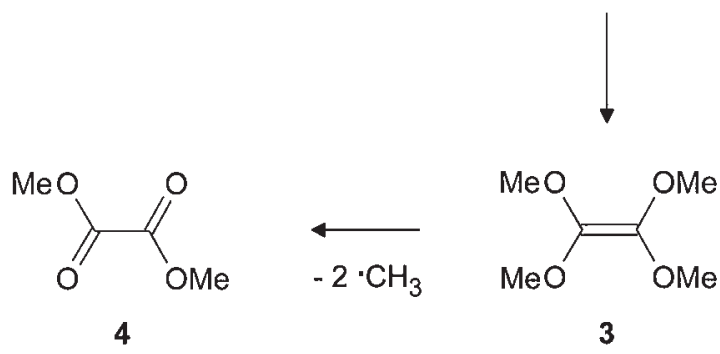

3

Fig. 1. He(I) photoelectron spectra of

(a) 2,2-dimethoxy-5,5-dimethyl- $\Delta^{3}$-1,3,4-oxadiazoline (1); (b) the pyrolysate of 1 obtained at a laser power level of $26 \mathrm{~W}$; (c) tetramethoxyethylene (3); (d) dimethoxycarbene (2) after subtraction (the hatched bands are due to ethane). Uniformly shifted calculated eigenvalues (Becke3LYP/6-31+G*) are given as vertical bars in $(a)$ and $(d)$.

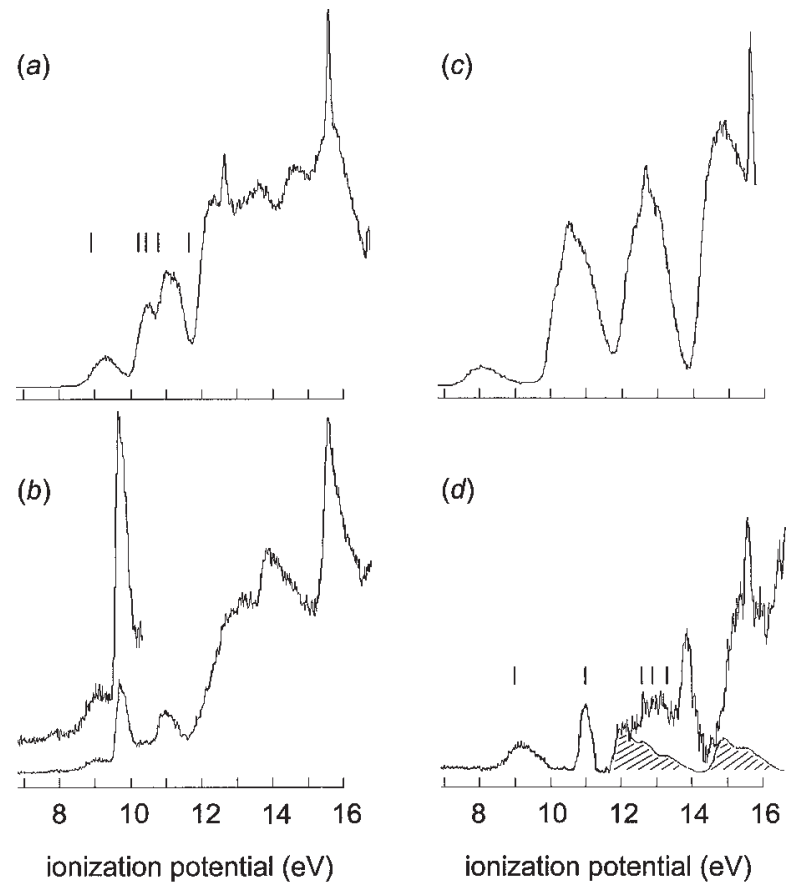

tetramethoxyethylene (3) (9) and preliminary flash vacuum pyrolysis experiments on 1 gave dimethyl oxalate (4), both of which could arise from a common precursor, dimethoxycarbene (2). Our recent computational study on the first adiabatic and vertical ionization potentials of carbenes (10) provided us with a calculational method (Becke3LYP/6-31+G* (11)) for the reliable prediction of these values. Applying these calculations to dimethoxycarbene (2), we expected to identify $\mathbf{2}$ through its ionization potentials if its spectrum actually was present in the pyrolysis spectrum of $\mathbf{1}$, and possibly to establish its conformation. The particular choice of oxadiazoline $\mathbf{1}$ for this study was made because $(a)$ it is a source of 2 ; $(b)$ it gave
Fig. 2. Preferred conformation (Becke3LYP/6-31+G*) of (a) oxadiazoline $\mathbf{1}$ and $(b)$ conformers $\mathbf{2} w$ and $\mathbf{2} s k$ of dimethoxycarbene. (a)

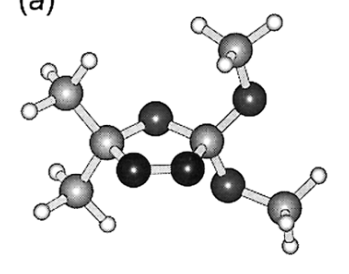

(b)

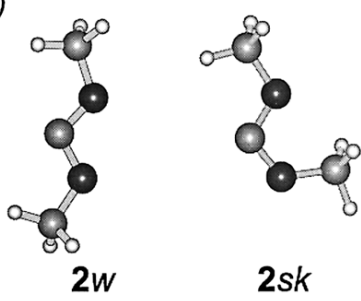

Table 1. Total energies $E_{\mathrm{T}}$ (hartrees) and calculated ionization potentials IP (eV) of optimized geometries of $\mathbf{1}-\mathbf{3}$ (N electrons) and their radical cations $\left(\mathrm{N}-1\right.$ electrons) according to Becke3LYP/6-31+ $\mathrm{G}^{*}$.

\begin{tabular}{llll}
\hline & $\begin{array}{c}\text { Number of } \\
\text { electrons }\end{array}$ & \multicolumn{1}{c}{$E_{\mathrm{T}}$} & IP \\
\hline $\mathbf{1}$ & $\mathrm{N}$ & -571.004434 & \\
$\mathbf{2} w$ & $\mathrm{~N}-1^{a}$ & -570.677705 & 8.89 \\
& $\mathrm{~N}$ & $-268.309870^{b}$ & \\
\multirow{3}{*}{$s k$} & $\mathrm{~N}-1^{c}$ & -268.011517 & 8.29 \\
& $\mathrm{~N}-1^{a}$ & -267.978827 & 9.01 \\
& $\mathrm{~N}$ & $-268.306911^{d}$ & \\
$\mathbf{3}$ & $\mathrm{N}-1^{c}$ & -268.008806 & 8.11 \\
& $\mathrm{~N}-1^{a}$ & -267.975877 & 9.01 \\
& $\mathrm{~N}$ & $-536.693043^{e}$ & \\
& $\mathrm{~N}-1^{c}$ & -536.445198 & 6.68 \\
& $\mathrm{~N}-1^{a}$ & -536.403737 & 7.87 \\
\hline
\end{tabular}

${ }^{a}$ Single-point energy calculation on the molecule's optimized geometry for $\mathrm{IP}_{\mathrm{v}}$.

${ }^{b} E_{\mathrm{T}}$ corrected for zero-point vibrational energy is -268.220668 .

${ }^{c}$ The geometry of the radical cation was optimized for $\mathrm{IP}_{\mathrm{a}}$.

${ }^{d} E_{\mathrm{T}}$ corrected for zero-point vibrational energy is -268.217754

${ }^{e}$ For the all-anti conformer.

us the additional opportunity to compare the mode of its decomposition (on a different path $\mathbf{1}$ can also yield nitrogen, dimethylcarbene, and dimethyl carbonate) in the gas phase to that in solution (9); and (c) it is the first member in a series of similar oxadiazolines that could be used as possible precursors of $\mathrm{O}, \mathrm{S}$ - and $\mathrm{O}, \mathrm{N}$-substituted carbenes in the gas phase. In this communication, we report the results of a $\mathrm{He}(\mathrm{I}) \mathrm{PE}$ spectroscopic study of the thermolysis of oxadiazoline $\mathbf{1}$ along with ab initio (Gaussian 94 (12)) calculational data on $\mathbf{1}$ and two of its pyrolysis products, dimethoxycarbene (2) and tetramethoxyethylene (3). PE spectra for $\mathbf{2}$ and $\mathbf{3}$ are presented for the first time.

The PE spectrum of $\mathbf{1}$ is shown in Fig. 1a. Three bands belonging to four ionizations (at 9.30, 10.49, 11.00, and 11.22 $\mathrm{eV}$ ) are separated from the main group of bands with its first band at about $12.1 \mathrm{eV}$. The sharp peak at $12.63 \mathrm{eV}$ belongs to traces of water. Vertical bars in Fig. $1 a$ give negative Becke3LYP/6-31+G* orbital energies $(-\varepsilon$ 6.81, 8.11, 8.33, 8.74 , and $9.49 \mathrm{eV}$ ), which are shifted so that the HOMO energy equals that of the calculated first vertical ionization potential $\operatorname{IP}_{\mathrm{v}}(8.89 \mathrm{eV}$; total energies are given in Table 1). Support for applying a Koopmans' Theorem-like interpretation of orbital energies at the DFT level of theory in PE spectroscopic studies has been provided by Arduengo et al. $(1 d)$. The most stable conformation of $\mathbf{1}$, with methoxy groups "sickle" as shown in Fig. $2 a$, was used in these calculations. 
The PE spectrum of the pyrolysate of $\mathbf{1}$ taken at a laser power level of $26 \mathrm{~W}$, which corresponds to a temperature of $500 \pm 50^{\circ} \mathrm{C}$ (3), is given in Fig. $1 b$. Besides nitrogen (sharp peak at $15.60 \mathrm{eV}$ ), the complex spectrum shows the prominent band of acetone (9.70 eV) (13). On its low-energy side, two bands of low intensity with maxima at 8.0 and $9.0 \mathrm{eV}$ can be attributed to further pyrolysis products. One path of decomposition of oxadiazoline $\mathbf{1}$ is given in Scheme 1. If nitrogen and acetone are two products, the remaining PE spectrum must be partially due to dimethoxycarbene (2) or to products arising from $\mathbf{2}$. When tetramethoxyethylene (3), the product of dimerization of 2, was prepared (14) and its PE spectrum (Fig. 1c) recorded, the first low-intensity band in the pyrolysis spectrum of $\mathbf{1}$ could be assigned to $\mathbf{3}$ (first IP at 8.0, shoulder at 10.1, and maximum of the second band at $10.5 \mathrm{eV}$ ). Interesting is the very broad first band of 3 : its $\mathrm{IP}_{\mathrm{a}}$ (first adiabatic ionization potential) is at $7.1 \mathrm{eV}$. Calculated Becke3LYP/6-31+G* first adiabatic and vertical IPs (Table 1) of the all-anti conformer, which is the global minimum according to $\mathrm{HF} / 3-21 \mathrm{G}$ calculations, match experimental values and confirm the energy difference between $\operatorname{IP}_{\mathrm{a}}$ and $\operatorname{IP}_{\mathrm{v}}$ found in the spectrum. Upon opening the fast-pumping valve on the spectrometer in the thermolysis of $\mathbf{1}$, the band at $8.0 \mathrm{eV}$ disappeared, which is proof that $\mathbf{3}$ is formed through dimerization of $\mathbf{2}$. To know whether $\mathbf{3}$ is stable at the thermolysis temperature (its thermal decomposition has been reported (15)), it was pyrolyzed in an independent experiment. The PE spectrum of the pyrolysate of 3 (not given) obtained at a laser power level of $26 \mathrm{~W}$ seems to be exclusively that of dimethyl oxalate (4) (16): IPs of bands are the same as those in a spectrum of an authentic sample of 4 taken with our spectrometer. The peak for the methyl radical (the literature value (17) is $9.84 \mathrm{eV}$ ) cannot be identified with certainty; it might be present on the low-energy side of the first band of 4.

When the PE spectra of acetone, tetramethoxyethylene (3), and dimethyl oxalate (4) were subtracted from the pyrolysis spectrum of $\mathbf{1}$, a simple spectrum remained. There are two bands of comparable intensity at 9.0 (onset at $8.4 \mathrm{eV}$ ) and 11.0 $\mathrm{eV}$, followed by an unstructured region with its first band at $12.0 \mathrm{eV}$ and a further maximum at $13.8 \mathrm{eV}$. These ionizations, except for the band at $12.0 \mathrm{eV}$, are reproduced nicely by Becke3LYP/6-31+G* calculations on dimethoxycarbene (2): for the $w$ conformer given in Fig. $2(b)$, which is more stable than the $s k$ conformer by $7.67 \mathrm{~kJ} \mathrm{~mol}^{-1}$ (or $7.64 \mathrm{~kJ} \mathrm{~mol}^{-1}$ when zero-point vibrational energies are included), $\mathrm{IP}_{\mathrm{a}}$ and $\mathrm{IP}_{\mathrm{v}}$ are 8.29 and $9.01 \mathrm{eV}$, respectively, and if orbital energies $(-\varepsilon$ 6 6.36 , $8.39,9.97$, and $10.34 \mathrm{eV}$ ) are shifted uniformly as explained above, the correlation is ideal (Fig. 1d). While data for the $s k$ conformer are not too different, $\mathrm{IP}_{\mathrm{a}} 8.11 \mathrm{eV}, \mathrm{IP}_{\mathrm{v}} 9.01 \mathrm{eV},-\varepsilon$ $6.36,8.71,9.80$, and $10.30 \mathrm{eV}$, a distinction between $2 w$ and $2 s k$ is possible by means of the second IP. The additional band at $12.0 \mathrm{eV}$ is the only obvious ionization not arising from 2. The facts that there are no bands unaccounted for in the lowenergy region of the spectrum and that methyl radicals are being formed in the thermolysis of $\mathbf{3}$ led us to assign this band to ethane (literature (13) IP is $11.99 \mathrm{eV}$ ). Additional support for this is supplied by subtraction of the PE spectrum of $\mathbf{4}$ from the pyrolysis spectrum of $\mathbf{3}$, which leaves a spectrum that has the features of that of ethane (13).

Neither were the products of a second possible path of decomposition of $\mathbf{1}$, dimethylcarbene (and from it propene) and dimethyl carbonate, detected in the pyrolysis PE spectrum, in agreement with results reported for the thermolysis of $\mathbf{1}$ in solution (9).

\section{Acknowledgment}

We gratefully acknowledge the usage of the IBM SP2 computer at Queen's University granted under the auspices of an IBM Canada - Queen's University collaborative project. We thank Ms. O. Donini for assistance with operational aspects of parallel Gaussian 94, and the Natural Sciences and Engineering Research Council of Canada (NSERC) for financial support. We also gratefully acknowledge the usage of the SGI computing installation in the Geochemistry Labs at McMaster funded by NSERC.

\section{References}

1. (a) D.W. Kohn, E.S.J. Robles, C.F. Logan, and P. Chen. J. Phys. Chem. 97, 4936 (1993); (b) H. Clauberg, D.W. Minsek, and P. Chen. J. Am. Chem. Soc. 114, 99 (1992); (c) J.M. Dyke, L. Golob, N. Jonathan, A. Morris, and M. Okuda. J. Chem. Soc. Faraday Trans. 2, 70, 1828 (1974); (d) A.J. Arduengo III, H. Bock, H. Chen, M. Denk, D.A. Dixon, J.C. Green, W.A. Herrmann, N.L. Jones, M. Wagner, and R. West. J. Am. Chem. Soc. 116, 6641 (1994).

2. R. Schulz and R. Schweig. In Structure and reactivity. Edited by J.F. Liebman and A. Greenberg. VCH Publishers Inc., New York. 1988. Chap. 8; N.P.C. Westwood. Chem. Soc. Rev. 18, 317 (1989); P. Chen. Unimol. Bimol. Ion-Mol. React. Dyn. 371 (1994)

3. N.H. Werstiuk, C.D. Roy, and J. Ma. Can. J. Chem. 72, 2537 (1994)

4. N.H. Werstiuk, C.D. Roy, and J. Ma. Can. J. Chem. 73, 146 (1995).

5. N.H. Werstiuk, J. Ma, and C.D. Roy. Can. J. Chem. 74, 1903 (1996).

6. N.H. Werstiuk, J. Ma, C.D. Roy, A.J. Kresge, and E.A. Jefferson. Can. J. Chem. 74, 2536 (1996).

7. N.H. Werstiuk, H.M. Muchall, J. Ma, and M.T.H. Liu. Can. J. Chem. Submitted.

8. K. Kassam, D.L. Pole, M. El-Saidi, and J. Warkentin. J. Am. Chem. Soc. 116, 1161 (1994).

9. M. El-Saidi, K. Kassam, D.L. Pole, T. Tadey, and J. Warkentin. J. Am. Chem. Soc. 114, 8751 (1992).

10. H.M. Muchall, N.H. Werstiuk, and B. Choudhury. Can. J. Chem. In press.

11. A.D. Becke. J. Chem. Phys. 98, 5648 (1993); C. Lee, W. Yang, and R.G. Parr. Phys. Rev. B: Condens. Matter, 37, 785 (1988).

12. M.J. Frisch, G.W. Trucks, H.B. Schlegel, P.M.W. Gill, B.G. Johnson, M.A. Robb, J.R. Cheeseman, T. Keith, G.A. Petersson, J.A. Montgomery, K. Raghavachari, M.A. Al-Laham, V.G. Zakrzewski, J.V. Ortiz, J.B. Foresman, C.Y. Peng, P.Y. Ayala, W. Chen, M.W. Wong, J.L. Andres, E.S. Replogle, R. Gomperts, R.L. Martin, D.J. Fox, J.S. Binkley, D.J. Defrees, J. Baker, J.P. Stewart, M. Head-Gordon, C. Gonzalez, and J.A. Pople. Gaussian 94, Revision B.3. Gaussian, Inc., Pittsburgh, Pa. 1995.

13. K. Kimura, K. Katsumata, Y. Achiba, T. Yamazaki, and S. Iwata. Handbook of HeI photoelectron spectra of fundamental organic molecules. Japan Scientific Societies Press, Tokyo, and Halsted Press, New York. 1981.

14. D. Belluš, H. Fischer, H. Greuter, and P. Martin. Helv. Chim. Acta, 61, 1784 (1978).

15. R.W. Hoffmann, J. Schneider, and H. Häuser. Chem. Ber. 99, 1892 (1966).

16. S.P. McGlynn and J.L. Meeks. J. Electron Spectrosc. Relat. Phenom. 8, 85 (1976).

17. L. Golob, N. Jonathan, A. Morris, M. Okuda, and K.J. Ross. J. Electron Spectrosc. Relat. Phenom. 1, 506 (1972-73). 